\title{
Review
}

Respiration 2013;85:515-520

DOI: $10.1159 / 000348269$
Received: December 7, 2012

Accepted after revision: January 17, 2013

Published online: March 12, 2013

\section{Collateral Ventilation}

\author{
D. Gompelmann R. Eberhardt F.J.F. Herth \\ Pneumology and Critical Care Medicine, Thoraxklinik at University of Heidelberg, Heidelberg, Germany
}

\section{Key Words \\ Collateral ventilation - Endoscopic lung volume reduction . Emphysema $\cdot$ Interlobar fissures $\cdot$ Pores of Kohn}

\begin{abstract}
Although known for more than 80 years, 'collateral ventilation' (CV) became a focus of endoscopic research in the recent decade. Implantation of one-way valves presents an effective treatment option for patients with advanced heterogeneous emphysema optimizing symptoms and quality of life. However, this treatment modality is only successful in case of low interlobar CV. Based on this evidence, attempts to develop different approaches for the quantification of $\mathrm{CV}$ have been initiated. In this regard, it is crucial to illuminate the meaning and different aspects of CV.
\end{abstract}

Copyright $\odot 2013$ S. Karger AG, Basel

\section{Introduction}

Collateral ventilation (CV) has moved to the center stage since the advent of endoscopic lung volume reduction (ELVR). The term 'collateral respiration' has already been mentioned by Van Allen et al. [1] in 1931 and thus can look back on a long history. However, it should be noted that in the meantime the term 'collateral ventilation' has different viewpoints that will be thoroughly examined in this review.

\section{KARGER}

(c) 2013 S. Karger AG, Base

0025-7931/13/0856-0515\$38.00/0

E-Mail karger@karger.com

www.karger.com/res

\section{Endoscopic Lung Volume Reduction}

The current meaning of CV is associated with ELVR that has emerged as a new treatment modality in patients with severe chronic obstructive lung disease and emphysema. Nowadays, various ELVR techniques are available which differ in their range of application and principle of action but share the same objective: a reduction in hyperinflation to improve respiratory mechanics in order to optimize pulmonary function, exercise capacity and quality of life. In general, blocking techniques and non-blocking techniques can be distinguished. Whereas the blocking techniques consist of implantation of one-way valves in the bronchi of the most emphysematous lung lobe, the nonblocking techniques exert different mechanisms of action [2]. Via coil implantation, parenchymal compression is achieved, while the polymeric lung volume reduction and the bronchoscopic thermal vapor ablation induce an inflammatory reaction in the target lobe with consequent fibrosis and shrinking of the affected lung compartment.

The implantation of one-way valves that allow the air to be expelled during expiration but not to enter during inspiration, which results in atelectasis in order to achieve lung volume reduction, was the first technique and therefore the best-studied method to date. The first reports on valve treatment were published by Toma et al. [3] and Snell et al. [4] in 2003. In the following years, several studies were performed. The biggest randomized multicenter trials, in which patients with emphysema were treated by endobronchial valves, were VENT [5] and Euro-VENT 


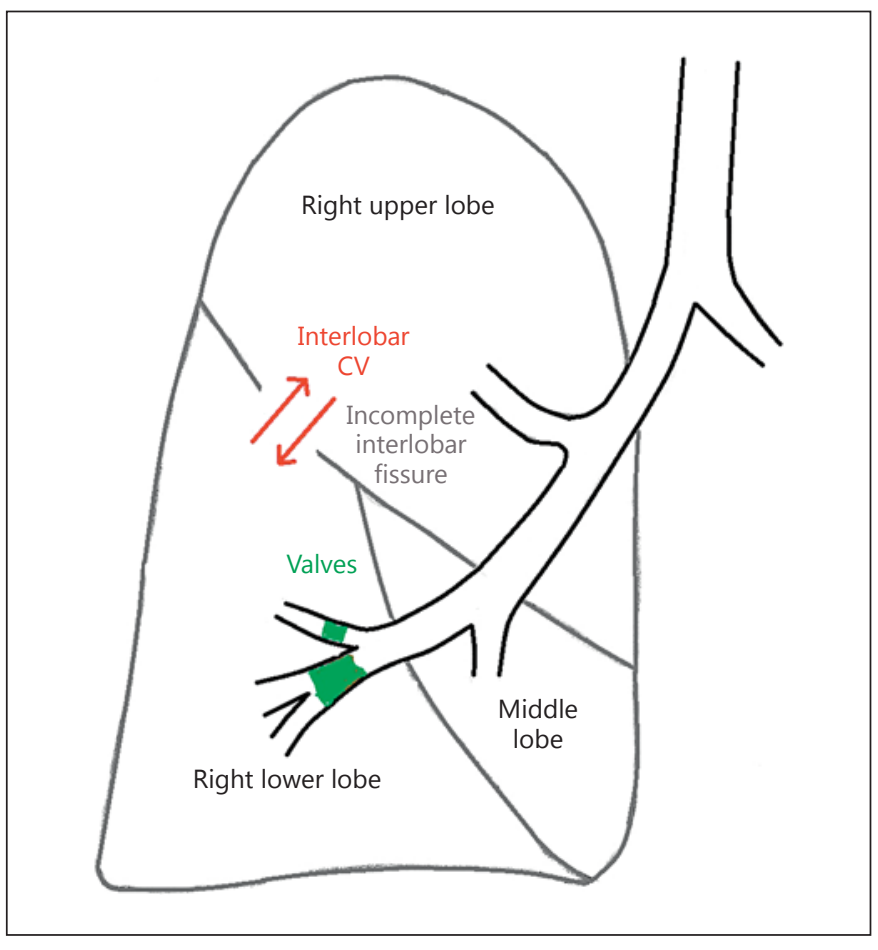

Fig. 1. Interlobar CV is responsible for the failure of valve treatment as occluded lobes are backfilled through collateral channels.

[6]. Both these studies confirmed modest efficacy of valve treatment. Subanalysis of these trials, however, revealed that particularly patients with complete interlobar fissures in the pre-interventional high-resolution computed tomography (HRCT) scan experienced good clinical outcome following valve implantation. Therefore, a complete interlobar fissure that is considered a surrogate of a low $\mathrm{CV}$ has emerged as a characteristic predicting a good outcome after valve treatment. An incomplete interlobar fissure, however, is associated with high CV that is responsible for the failure of valve treatment (fig. 1). Besides fissure analysis on $\mathrm{CT}$, a catheter-based measurement was developed to assess CV. This measurement is performed during bronchoscopy using a catheter placed in the airway of the target lung lobe. By isolating this lung area through a balloon situated at the tip of the catheter, airflow and air pressure is measured and resistance of collateral channels can be calculated. The accuracy of this catheter-based CV measurement was found to be $90 \%$ in a trial evaluating the safety of this catheter-based system and the feasibility of the obtained measurements [7] in 20 patients, and in a subsequent multicenter trial in 80 patients accuracy was $75 \%$ [8]. These results demonstrate that CV is a crucial factor for the outcome of valve treatment.

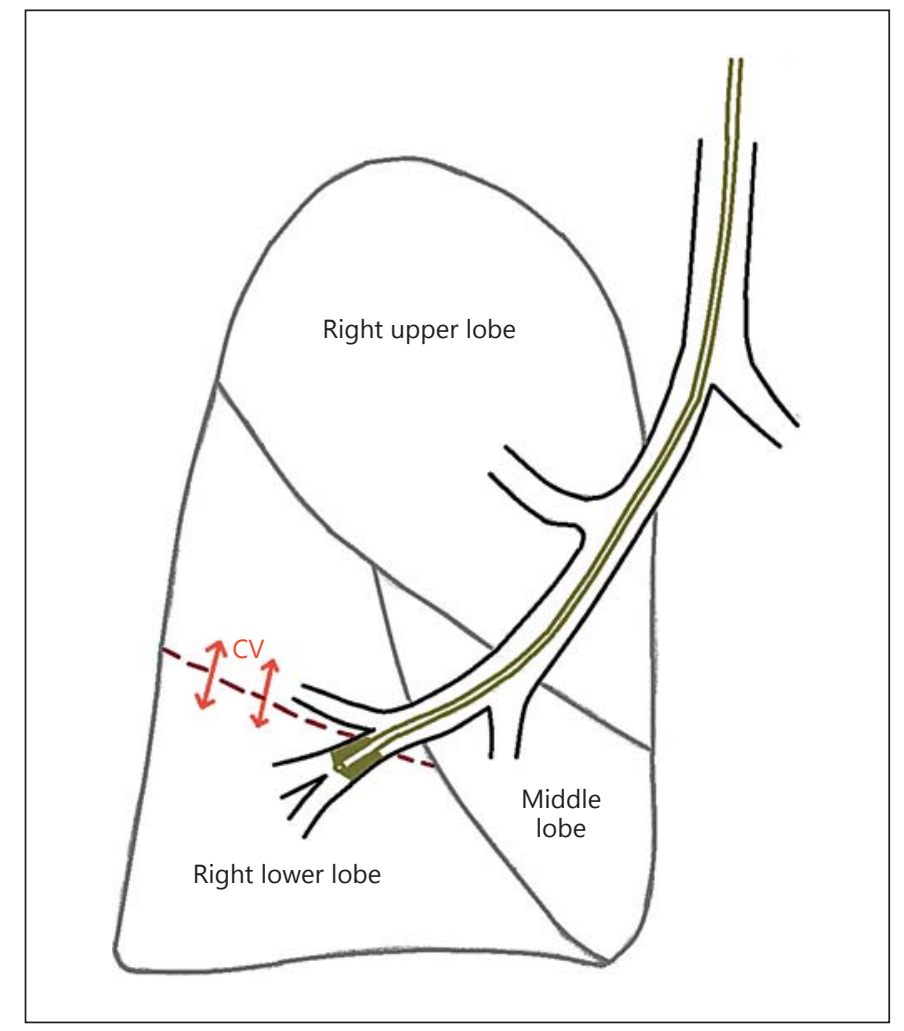

Fig. 2. Van Allen et al. [1] examined interlobular CV. One cannula is inserted in one lobule of the right lower lobe. Through this cannula, air was injected. A second cannula (not shown in this figure) with its distal end submerged into water was inserted into the same lobe supplying the remainder of this lobe. Injection of air through the first cannula led to a stream of water bubbles (modified from Van Allen et al. [1]).

In contrast to the valve therapy, the non-blocking techniques are independent of $\mathrm{CV}$. One retrospective analysis of a multicenter trial dealing with the bilateral implantation of coils in patients with severe emphysema revealed that a subgroup of patients, in whom incomplete fissures were retrospectively assessed using pre-interventional HRCT, achieved a similar good clinical outcome following coil implantation as the whole study population [9]. Bronchoscopic thermal vapor ablation (BTVA) and Polymeric Lung Volume Reduction (PLVR) are also independent of CV. Regarding BTVA, CT data of 44 patients with heterogeneous emphysema treated with BTVA were retrospectively analyzed. The results revealed that the effects of BTVA on lung volume reduction and improvement in clinical outcome were negligible [10]. Another study provided comparable results with respect to PLVR [11]. 


\section{What Exactly Is ‘Collateral Ventilation’?}

The term comes from the latin 'con', 'latus' and 'ventilare' and stands for 'side to side' and 'ventilate'. This means nothing less than that the alveoli are situated next to each other and that air can pass through the wall from one alveolus into another alveolus.

Van Allen et al. [1] were the first to mention the term 'collateral respiration' in 1931 [1]. They performed human and animal experiments in vitro as well as in vivo to evaluate CV. To cite only one of his approaches in vitro in detail (fig. 2): in prepared lungs, he advanced first a cannula in one bronchus of the right lower lobe so that this cannula supplied a single lobule. Through this cannula, air was injected. A second cannula with its distal end submerged into water was inserted into the same lobe supplying the remainder of that lobe. When air was injected through the first cannula into one lobule of the lobe, the air passed into the other lobules and escaped from the second cannula in a continuous stream of water bubbles. In this manner, air passage between adjacent lobules of one lobe was evidenced. Based on this and similar experimental approaches, Van Allen et al. [1] hypothesized that in human beings collateral respiration occurs between adjacent lobules of the same lobe but not between adjacent lobules of different lobes, because the interlobular septa would be very thin and incomplete, whereas the interlobar septa would be thick and complete. Furthermore, they assumed that the pores of Kohn and to a lesser extent diffusion were responsible for the occurrence of collateral respiration.

\section{Pores of Kohn}

The German physician Hans Kohn [12] was the first to describe alveolar pores in 1893 . He revealed fibrin strands entering the alveolar wall from one alveolus into the adjacent alveolus in a lung preparation of a patient who died of organizing pneumonia $[13,14]$. He did not use the term 'pores of Kohn' himself, but his tutor Gustav Hauser [15] named these interalveolar pores as 'pores of Kohn' in 1894. The pores of Kohn allow the passage of air, alveolar lining fluid and cells between adjacent alveoli. Electron-microscopic studies confirmed the existence of the pores of Kohn by demonstrating intact epithelium-lined alveolar walls shaping the pores $[13,14]$. In most of these studies, examinations were performed in instillation-fixed, dried lungs showing widely opened pores. Low-temperature scanning elec-

Collateral Ventilation tron microscopy in frozen sections of hydrated lungs, however, enables better preservation of the normal alveolar lining layer and thus reflects most likely the in vivo status [13]. In one of these low-temperature scanning electron microscopy studies, which was published 20 years ago, the number of empty pores detected were significantly reduced in comparison to conventional electron-microscopic studies in dried and fixed lungs. Thus, it seems that in vivo the pores are mostly filled by fluid and are only opened in case of a large pressure gradient across the pores [13]. Therefore, the authors hypothesized that the pores of Kohn do not function as channels for $\mathrm{CV}$ but function primarily as pathway for alveolar lining fluid, surfactant components and cells like macrophages between the adjacent alveoli. Alveolar ducts or respiratory bronchioles are the most likely responsible for CV. Such alveolar ducts are Lambert channels that represent epithelium-lined tubular communications between distal bronchioles and the adjacent alveoli. These channels were described by Lambert [16] in 1955. She reported that in lungs of coal miners dust accumulations in alveoli were found to be in continuity with those in bronchioles. The other channels that are responsible for CV are the pathways which Martin [17] explored in 1966. These pathways are accessory communications between terminal bronchioles from adjacent lung segments. Thus, bronchioloalveolar as well as interbronchiolar channels are considered to allow collateral respiration.

\section{For What Is CV Necessary?}

In lung compartments no longer supplied by airways due to their pathological alterations, ventilation can be maintained by $\mathrm{CV}$. In the absence of CV, airway obstruction would finally lead to atelectasis. In their previous experiments, Van Allen et al. [1] have already spotted that obstructive pulmonary atelectasis did not occur in every case and thus set up a hypothesis on the occurrence of CV, but they also noted that $\mathrm{CV}$ was not present in all living beings. He discovered CV in humans, dogs and cats but not in calves and pigs [1].

Humans develop interalveolar, bronchioalveolar and interbronchiolar pathways during the first 5 years of life [18]. Consequently, in children under the age of 5 years, asthmatic symptoms or obstructive bronchitis are more often present. In healthy lungs, however, the importance of $\mathrm{CV}$ in the distribution of ventilation is negligible because the resistance to airflow is higher in the collateral 
channels than in the airways [19], but its importance increases in case of obstructive processes like chronic obstructive pulmonary disease, tumor obstruction or airway occlusion by foreign bodies.

Morrell et al. [20] assessed CV in 6 patients with emphysema and 12 healthy volunteers. In their experimental study, all study participants underwent flexible bronchoscopy. A balloon-tipped catheter connected to a respiratory mass spectrometer was introduced into the airways. Following balloon inflation, a selected segmental bronchus was isolated and the exhaled air of the isolated compartment was determined. Afterwards, breathing air was changed to $21 \%$ oxygen $/ 79 \%$ helium for a certain time period. Detection of helium in the occluded lung area implied the presence of CV. The results of this study revealed that in patients with emphysema $\mathrm{CV}$ exceeded approximately ten times that in healthy controls.

\section{Are the Pores of Kohn, Channels of Lambert and Pathways of Martin Responsible for ELVR Failure by Valve Treatment?}

As described previously, the hypothesis was set up that the pores of Kohn function primarily as pathways for alveolar lining fluid, whereas the bronchioloalveolar as well as interbronchiolar channels may facilitate collateral respiration. However, it must be borne in mind that particularly Van Allen et al. reported about interlobular CV [1]. In the issue of ELVR, however, not the interlobular but the interlobar $\mathrm{CV}$ is considered responsible for the failure of valve treatment. The authors even emphasized that in humans the interlobar septa are very thick and complete and thus do not allow collateral respiration. Present studies, however, indicate that the interlobar fissures are indeed frequently incomplete. Surgery as well CT studies established fusion of adjacent lobes (fig. 3, 4) [21]. To date, there are no data related to the histology of these parenchymal bridges, but it can be assumed that normal tissue of parenchymal bridges also presents pores of Kohn, channels of Lambert and pathways of Martin. Therefore, these pathways play certainly a role in interlobar communication. However, it remains to be determined if these channels form the basis of the interlobar fusion and collateral respiration. Until now, the genesis of interlobar parenchymal bridges is unclear. Do incomplete fissures exist since birth or do the parenchymal bridges develop during life? Are these incomplete fissures more frequent in patients with lung disease than in healthy humans?
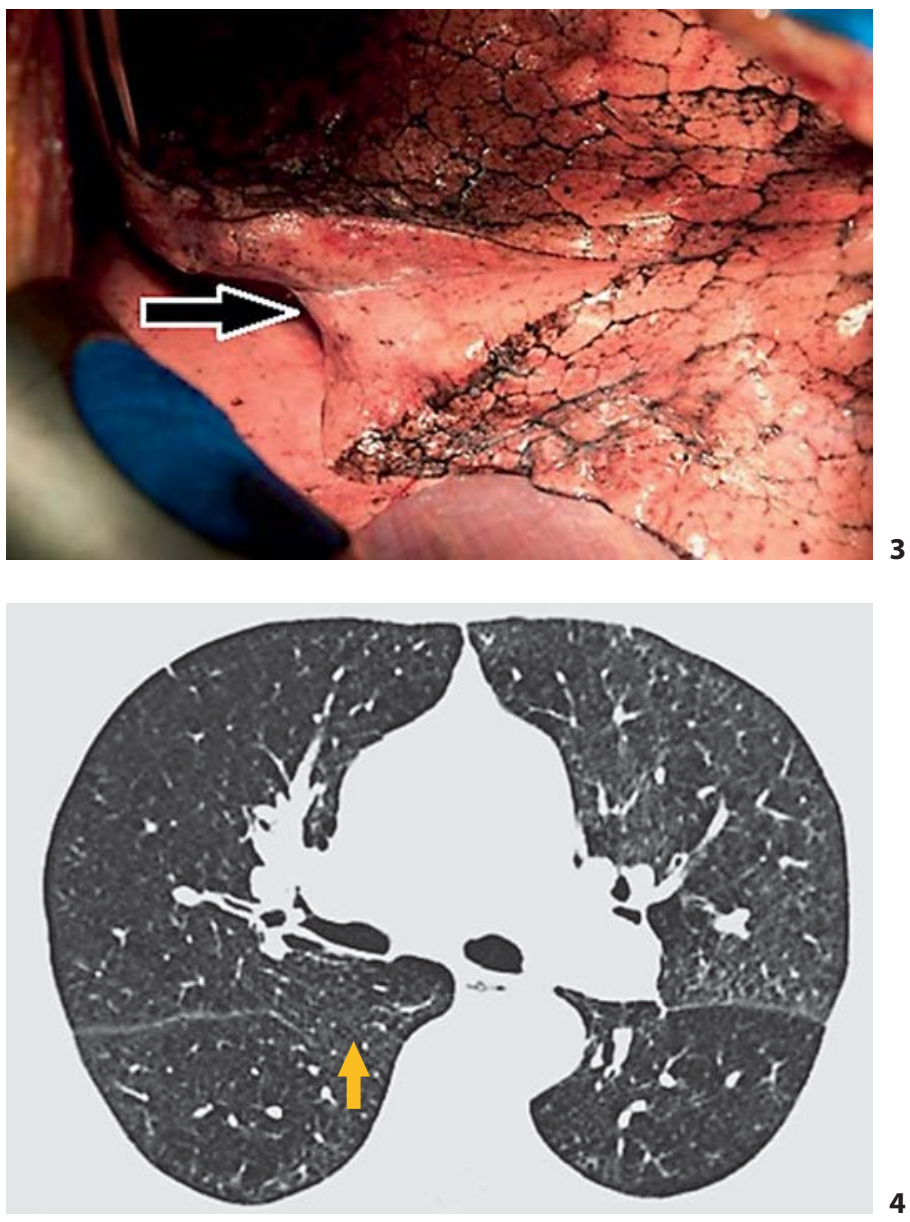

Fig. 3, 4. Incomplete interlobar fissure observed during surgery (3; by courtesy of $\mathrm{H}$. Dienemann) and CT fissure analysis (4; by courtesy of C.P. Heussel).

\section{Interlobar Fissure Analysis}

In a trial by Aziz et al. [22] in 622 healthy humans and patients with pulmonary disease but without significant effect on fissures, interlobar fissure completeness was precisely analyzed using HRCT. The authors revealed that the left major fissure was incomplete in $43 \%$ and the right major fissure in $48 \%$. The right minor fissure was most commonly incomplete (in 63\%). Further radiological trials evaluating fissure completeness showed similar results in healthy humans and patients with mild lung disease [23-25]. Therefore, it seems that fissure incompleteness is a normal phenomenon in healthy humans without pathological meaning. A key question is if the interlobar fissures of patients who suffer from severe pulmonary disease are more often incomplete than in healthy subjects. To answer this crucial question, the results of a 
trial published in 2012 can be used, although the main focus of this trial was another issue. In this study, an automatic method was applied to quantify fissure completeness in 96 patients with severe emphysema [26]. The left major fissure was incomplete in $33 \%$ of the cases, the right major fissure in $51 \%$ and the right minor fissure in $85 \%$ of the cases. Thus, fissure incompleteness of the emphysema patients was similar compared to the results of the other previously mentioned studies on fissure incompleteness in healthy subjects.

\section{Are Incomplete Interlobar Fissures a Surrogate for CV?}

Van Allen et al. [1] have already suggested that there is no or only negligible interlobar CV in humans because the interlobar fissures are very thick. Thereby, they suspected a relationship between fissures and CV. Even nowadays, incomplete fissures are considered as a surrogate for high CV. What needs to be analyzed is whether there is a correlation between fissure completeness and CV.

A previously described option to quantify $\mathrm{CV}$ is the invasive catheter-based measurement using the Chartis ${ }^{\circledR}$ pulmonary assessment system. This system consists of two compartments with a catheter and a console. At the tip of the catheter, there is a balloon that can be inflated within the bronchi to isolate a lung area. Thus, airflow and pressure can be determined in this target compartment, and resistance in the collateral channels can be calculated. The aim of one retrospective subanalysis of one multicenter study [8] was to evaluate whether the use of the Chartis ${ }^{\circledR}$ pulmonary assessment system is a comparable and efficient equivalent to $\mathrm{CT}$ fissure analysis to predict target lobe volume reduction with endobronchial valve therapy [27]. In this study, CV was determined in patients using the Chartis ${ }^{\circledR}$ pulmonary assessment system followed by a complete obstruction of the target lobe by endobronchial valves. Thirty days following the intervention, a HRCT scan was performed to assess the target lobe volume reduction. Retrospectively, fissures were evaluated in the pre-procedure HRCT scans. A CV-negative result was considered to be comparable to a complete fissure on CT, while a CV-positive result was considered comparable to an incomplete fissure. The Chartis ${ }^{\circledR}$ system readings and CT readings were compared for how often they 'matched', and the predictive value of each technology was compared to the outcome of target lobe volume reduction. Of a total of 70 patients enrolled, 52 patients responded as predicted when the Chartis ${ }^{\circledR}$ sys- tem was used, whereas 54 patients responded as predicted when CT fissure analysis was performed. Of the 48 times the Chartis system and CT fissure analysis matched, the patients responded as predicted in 42 (88\%) cases. Therefore, it seems that incomplete fissures are associated with high CV and vice versa.

In another prospective study already published in 2006 by Higuchi et al. [28], associations between different characteristics, e.g. patient characteristic, fissure completeness, emphysema heterogeneity and degree of interlobar $\mathrm{CV}$, were evaluated. The authors examined 23 lungs of 17 patients with emphysema who underwent lung transplantation. Data on demographic characteristics, lung function tests and radiological procedures were collected. Furthermore, CT and ventilation/perfusion scan scoring was used to evaluate heterogeneity indexes of emphysema. After explantation, the lungs were first examined to assess lobar anatomy and fissure completeness. Afterwards, the degree of $\mathrm{CV}$ was evaluated using the following approach: The explanted lung was intubated with a tube that was advanced into one lobe after another. Each lobe was selectively inflated. CV was present if the non-intubated lobes were inflated passively. Surprisingly, the results revealed that there was only a significant relationship between the heterogeneity of emphysema and the degree of CV. It was suggested that CV occurs to a greater extent in homogeneous emphysema than in heterogeneous disease. There was no correlation between the macroscopically analyzed fissure in the explanted lung and the extent of CV.

However, it must be borne in mind that these examinations were performed in ex vivo lungs. Another limitation of the study is the small number of lungs examined, which does not allow to draw a general conclusion. Nevertheless, aiming to explain these results, let us have a look back on the study by Van Allen et al. [1] in 1931. They set up the hypothesis that collateral respiration depends not only upon interalveolar and interbronchiolar pathways but also to some degree on diffusion.

In summary, CV seems to influence the outcome of endoscopic valve treatment in patients with severe emphysema, but the mechanisms of action of CV remain to be determined. Regarding the results of the previously mentioned VENT and Euro-VENT, it can be assumed that completeness of interlobar fissures is a crucial factor predicting a good clinical outcome following valve treatment. As already identified in the above-described retrospective study, it seems that interlobar fissures can be considered as surrogate markers of CV. Nevertheless, some details on CV are still unclear and therefore further studies are obviously required. 


\section{References}

$>1$ Van Allen CM, Lindskog GE, Richter HG: Collateral respiration. Transfer of air collaterally between pulmonary lobules. J Clin Invest 1931;10:559-590.

-2 Herth FJ, Gompelmann D, Ernst A, Eberhardt R: Endoscopic lung volume reduction. Respiration 2010;79:5-13.

$\checkmark 3$ Toma TP, Hopkinson NS, Hillier J, Hansell DM, Morgan C, Goldstraw PG, Polkey MI, Geddes DM: Bronchoscopic volume reduction with valve implants in patients with severe emphysema. Lancet 2003;361:931-933.

4 Snell GI, Holsworth L, Borrill ZL, Thomson KR, Kalff V, Smith JA, Williams TJ: The potential for bronchoscopic lung volume reduction using bronchial prostheses: a pilot study. Chest 2003;124:1073-1080.

5 Sciurba FC, Ernst A, Herth FJF, Strange C, Criner GJ, Marquette CH, Kovitz KL, Chiacchierini RP, Goldin J, McLennan G, VENT Study Research Group: A randomized study of endobronchial valves for advanced emphysema. N Engl J Med 2010;363:1233-1244.

6 Herth FJ, Noppen M, Valipour A, Leroy S, Verngnon JM, Ficker JH, Egan JJ, Gasparini S, Agusti C, Holmes-Higgin D, Ernst A, Interventional VENT Study Group: Efficacy predictors of lung volume reduction with Zephyr valves in a European cohort. Eur Respir J 2012;39:1334-1342.

7 Gompelmann D, Eberhardt R, Michaud G, Ernst A, Herth FJ: Predicting atelectasis by assessment of collateral ventilation prior to endobronchial lung volume reduction: a feasibility study. Respiration 2010;80:419-425.

-8 Herth FJ, Eberhardt R, Gompelmann D, Ficker JH, Wagner M, Ek L, Schmidt B, Slebos DJ: Radiological and clinical outcomes of using Chartis to plan endobronchial valve treatment. Eur Respir J 2013;41:302-308.

-9 Gompelmann D, Eberhardt R, Goldin J, Slebos DJ, Gesierich W, Pfeifer M, Herth FJF: Endoskopische Lungenvolumenreduktion mittels Coil-Implantation bei Patienten mit schwerem heterogenem Lungenemphysem und inkompletten Fissuren: eine retrospektive Analyse. Pneumologie 2012;66:P428.
10 Gompelmann D, Heussel CP, Eberhardt R, Snell G, Hopkins P, Baker K, Witt C, Valipour A, Wagner M, Stanzel F, Egan J, Kesten S, Herth FJ: Efficacy of bronchoscopic thermal vapor ablation and lobar fissure completeness in patients with heterogeneous emphysema. Respiration 2012;83:400-406.

11 Magnussen $\mathrm{H}$, Kramer MR, Kirsten AM, Marquette C, Valipour A, Stanzel F, Bonnet R, Behr J, Fruchter O, Refaely Y, Eberhardt R, Herth FJ: Effect of fissure integrity on lung volume reduction using a polymer sealant in advanced emphysema. Thorax 2012;67:302308.

12 Kohn HN: Zur Histologie des indurierenden fibrinösen Pneumonie. Münch Med Wochenschr 1893;40:42-45.

13 Backstacky J, Goerke J: Pores of Kohn are filled in normal lungs: low-temperature scanning electron microscopy. Appl Physiol 1992; 73:88-95.

14 Cordingley JL: Pores of Kohn. Thorax 1972; 27:433-441.

15 Hauser G: Ueber die Entstehung des fibrinösen Infiltrates bei der croupösen Pneumonie. Beitr Path Anat 1894;15:527

16 Lambert MW: Accessory bronchiole-alveolar communications. J Pathol Bacteriol 1955; 311-124.

17 Martin HB: Respiratory bronchioles as the pathway for collateral ventilation. J Appl Physiol 1966;21:1443-1447.

18 Fehrenbach H: Entwicklung der kindlichen Lunge. Elektronenmikroskopie - Ultrastruktur der menschlichen Lunge; in Riedl-Seifert RJ (eds): Vom Wheezing Child zur COPD. München, Zuckschwerdt, 2004.

19 Rosenberg DE, Lyons AH: Collateral ventilation in excised human lungs. Respiration 1979;37:125-134
20 Morrell NW, Wignall BK, Biggs T, Seed WA: Collateral ventilation and gas exchange in emphysema. Am J Respir Crit Care Med 1994; 150:635-641.

21 Venuta F, Rendina EA, De Giacomo T, Flaishman I, Guarino E, Ciccone AM, Ricci C: Techniques to reduce air leaks after pulmonary lobectomy. Eur J Cardiothorac Surg 1998;13:361-364.

22 Aziz A, Ashizawa K, Nagaoki K, Hayashi K: High resolution CT anatomy of the pulmonary fissures. J Thorac Imaging 2004;19:186191.

$>23$ Gülsün $M$, Ariyürek OM, Cömert RB, Karabulut N: Variability of the pulmonary oblique fissures presented by high-resolution computed tomography. Surg Radiol Anat 2006;28:293-299.

24 Cronin P, Gross BH, Kelly AM, Patel S, Kazerooni EA, Carlosc RC: Normal and accessory fissures of the lung: evaluation with contiguous volumetric thin-section multidetector CT. Eur J Radiol 2010;75:1-8.

25 Ozmen CA, Nazaroglu H, Bayrak AH, Senturk S, Akay HO: Evaluation of interlobar and accessory pulmonary fissures on 64-row MDCT. Clin Anat 2010;23:552-558.

26 van Rikxoort EM, Goldin JG, Galperin-Aizenberg M, Abtin F, Kim HJ, Lu P, van Ginneken B, Shaw G, Brown MS: A method for the automatic quantification of the completeness of pulmonary fissures: evaluation in a database of subjects with severe emphysema. Eur Radiol 2012;22:302-309.

27 Gompelmann D, Eberhardt R, Slebos DJ, Ficker JH, Wagner M, Reichenberger F, Ek L, Schmidt B, Herth FJF: Study of the use of Chartis ${ }^{\circledR}$ pulmonary assessment system as a predictor of collateral ventilation as compared to computed tomography (abstract 373). ERS 2011.

-28 Higuchi T, Reed A, Oto T, Holsworth L, Ellis S, Bailey MJ, Williams TJ, Snell GI: Relation of interlobar collaterals to radiological heterogeneity in severe emphysema. Thorax 2006;61:409-413. 